\title{
РЕААКЦИОННАЯ СТАТЬЯ
}

DOI: https://doi.org/10.17816/psaic650

\section{БОАЕЗНИ ЖЕАЧНОГО ПУЗЫРЯ У АЕТЕЙ СОВРЕМЕННЫЙ ВЗГАЯА АЕТСКОГО ХИРУРГА (СИСТЕМАТИЧЕСКИЙ ОБЗОР)}

\author{
(С) II.С. Питер ${ }^{1}$ Ю.А. Козлов ${ }^{2,3,4 凶}$ \\ ${ }^{1}$ Отделение детской хирургии, Детский госпиталь Благодарения, Канзас-Сити, США; \\ 2 Областное государственное автономное учреждение здравоохранения «Городская Ивано- \\ Матренинская детская клиническая больница», Иркутск, Россия; \\ ${ }^{3}$ Иркутская государственная медицинская академия последипломного образования - филиал \\ Федерального государственного бюджетного образовательного учреждения дополнительного \\ профессионального образования «Российская медицинская академия непрерывного \\ профессионального образования» Министерства здравоохранения Российской Федерации, \\ Иркутск, Россия; \\ ${ }^{4}$ Федеральное государственное бюджетное образовательное учреждение высшего \\ профессионального образования «Иркутский государственный медицинский университет» \\ Министерства здравоохранения Российской Федерации, Иркутск, Россия
}

- Аля цитирования: Питер Ш.С., Козлов Ю.А. Болезни желчного пузыря у Аетей - современный взглял Аетского хирурга (систематический обзор) // Российский вестник Аетской хирургии, анестезиологии и реаниматологии. - 2020. - Т. 10. - № 1. - С. 7-16. DOl: https://doi.org/10.17816/psaic650

В настоящее время двумя основными причинами заболеваний желчного пузыря у детей являются дискинезия желчевыводящих путей и образование камней желчного пузыря. Дискинезия желчевыводящих путей является самостоятельным заболеванием и обусловлена, в основном, гипомоторикой желчного пузыря, приводящей к его недостаточно полному опорожнению и сопровождающейся хроническим болевым абдоминальным синдромом. Причины образования камней у детей отличаются от этиопатогенеза камнеобразования у взрослых. Нарушения метаболизма, в основном на фоне ожирения, приводят к образованию холестериновых камней, как наиболее распространенной причины желчнокаменной болезни у детей. Другим фактором холелитиаза являются заболевания крови, сопровождающиеся гемолизом, такие как серповидноклеточная анемия, наследственный сфероцитоз и талассемия. Симптомы заболеваний желчного пузыря проявляются, прежде всего, хроническим абдоминальным болевым синдромом. Воспаление желчного пузыря относительно редкая форма течения желчнокаменной болезни у детей. Актуальной технологией лечения заболеваний желчного пузыря у детей, как и у взрослых, является холецистэктомия, которая может реализоваться в зависимости от степени владения эндохирургическими навыками с помощью стандартной четырехпортовой лапароскопической техники или единого лапароскопического доступа. В настоящем обзоре рассматриваются вопросы семиотики, этиологии, диагностики и хирургического лечения детей с заболеваниями желчного пузыря. Систематизированный обзор литературы содержит ответы на дискуссионные вопросы, касающиеся диагностики дискинезии желчных путей, в том числе при сопутствующем холедохолитиазе, обоснования эффективной хирургической тактики.

Ключевые слова: желчный пузырь; дети; дискинезия желчевыводящих путей; желчнокаменная болезнь; холецистэктомия; лапароскопия. 


\title{
DISEASES OF THE GALLBLADDER IN CHILDREN - MODERN VIEW OF PEDIATRIC SURGEON (SYSTEMATIC REVIEW)
}

\author{
(C) Sh.St. Peter', Yu.A. Kozlov ${ }^{2,3,4}$ \\ ${ }^{1}$ Department of Pedaiatric Surgery, Childrens Mercy Hospital, Kansas City, USA; \\ ${ }^{2}$ Irkutsk municipal pediatric clinical hospital, Irkutsk, Russia; \\ ${ }^{3}$ Irkutsk State Medical Academy of Continuing Education, Irkutsk, Russia; \\ ${ }^{4}$ Irkutsk State Medical University Russia, Irkutsk, Russia
}

- For citation: St. Peter S, Kozlov YuA. Diseases of the gallbladder in children - modern view of pediatric surgeon (systematic review). Russian J oumal of Pediatric Surgery, Anesthesia and Intensive Care. 2020;10(1):7-16. DOl: https://doi.org/10.17816/psaic650

Currently, the two main causes of diseases of the gallbladder in children are biliary dyskinesia and the formation of gallbladder stones. Biliary dyskinesia is an independent disease and is caused mainly by reduced motility of the gallbladder, which leads to its insufficiently good emptying and is accompanied by chronic pain abdominal syndrome. The causes of stone formation in children differ from the sources of stone formation in adults. Metabolic disorders, mainly against the background of obesity, lead to the formation of cholesterol stones, which is the most common cause of cholelithiasis in children. Blood diseases is another factor of cholelithiasis associated with hemolysis, such as sickle cell anemia, hereditary spherocytosis, and thalassemia. Symptoms of gallbladder disease are mainly in chronic abdominal pain syndrome. Inflammation of the gallbladder is a fairly rare form of the course of gallstone disease in children. The current surgical technology for treatment of gallbladder diseases in children, as in adults, is cholecystectomy, which can be realized depending on the degree of mastery of endosurgical skills using standard four-port laparoscopic techniques or a single laparoscopic approach. This review addresses the issues of semiotics, etiology, diagnosis, and surgical treatment of gallbladder disease in pediatric patients. The scientific work answers many controversial questions regarding the diagnosis of biliary dyskinesia, the choice of diagnostic method for concomitant choledocholithiasis, and the selection of the most effective surgical approach.

Keywords: gall bladder; children; biliary dyskinesia; gallstone disease; cholecystectomy; laparoscopy.

\section{BBEАЕНИЕ}

В последние десятилетия частота заболеваний желчного пузыря в детском возрасте неуклонно возрастает. Исторически, эти болезни у детей были связаны с образованием камней в желчном пузыре, в основном, на фоне гемолитических синдромов. Однако в наши дни рост частоты желчнокаменной болезни в основном индуцирован современной диетой, приводящей к нарушениям метаболизма и детскому ожирению. Эти тренды являются характерными, прежде всего, для экономически развитых стран.

Основными причинами заболеваний желчного пузыря у детей являются образование камней желчного пузыря и дискинезия желчевыводящих путей. Независимо от этиологии, у пациентов обеих групп присутствуют сходные симптомы. Основным симптомом является боль, обычно в правом верхнем квадранте, которая может перемещаться в эпигастральную область. Чаще боли возника- ют после еды и нередко связаны с приемом жирной пищи. Боль может сопровождаться тошнотой, иногда рвотой, и в некоторых случаях иррадиирует в спину. Это сочетание симптомов обычно называют желчной коликой, доставляющей детям значительный дискомфорт. При пальпации живота иногда наблюдается легкая болезненность в правом подреберье в «точке желчного пузыря». Если возникает острое воспаление желчного пузыря, боль, как правило, достигает такой выраженности, что становится невыносимой, заставляя пациентов обращаться за неотложной помощью.

\section{БИАИАРНАЯ АИСКИНЕЗИЯ}

Рост регистрируемой частоты заболеваний желчного пузыря у детей в значительной степени связан с совершенствованием диагностики и, соответственно, своевременным лечением пациентов с дискинезией желчевыводящих путей [1-3]. Дискинезия желче- 
выводящих путей является нозологической формой, отличной по клиническим проявлениям от других абдоминальных болевых синдромов. Однако ее происхождение до настоящего времени не уточнено $[4,5]$. Гипотетическим является утверждение, что гипоактивный желчный пузырь недостаточно полно опорожняется, что приводит к возникновению хронического болевого абдоминального синдрома. Поскольку дискинезия желчевыводящих путей не существенно отличается от других причин болей в животе, обследование пациента начинается с лабораторных исследований, рентгенографии и ультразвукового сканирования. Лабораторные исследования включают полный анализ клеток крови и функциональные печеночные тесты с определением амилазы и липазы. Рентгенография брюшной полости полезна только в том случае, если симптомы связаны с признаками кишечной непроходимости. Ультразвуковое исследование (УЗИ) идентифицирует анатомическую причину боли у пациентов с холелитиазом и редко обнаруживает ее у больных дискинезией желчевыводящих путей, несмотря на то что у последних могут быть выявлены изменения в лабораторных показателях. Следующим шагом для верификации диагноза дискинезии желчного пузыря обычно является радионуклидное сканирование печени с использованием иминодиуксусной кислоты (HIDA) со стимуляцией холецистокинином (CСK). После периода голодания, длящегося на протяжении 6 ч, пациенту вводят внутривенно в виде инъекции 99-Тс меченный аналог иминодиуксусной кислоты. Когда происходит максимальное заполнение желчного пузыря, внутривенно в течение 60 мин вводится холецистокинин, и затем рассчитывается фракция выброса желчного пузыря. Фракция выброса желчного пузыря менее $35 \%$ традиционно рассматривается в качестве диагностического порога установления диагноза «дискинезия желчевыводящих путей» [6]. Единственное на сегодняшний день эффективное лечение дискинезии желчевыводящих путей - лапароскопическая холецистэктомия. Обычно, это - стандартная операция при отсутствии воспаления стенок желчного пузыря. Результаты данных операций благоприятны и характеризуются крайне низким риском инфицирования брюшной полости, желчеистечения и повреждения желчных путей [7]. Истинная проблема у этих пациентов заключается в том, что неизвестно, приведет ли удаление желчного пузыря к улучшению и исчезновению симптомов. Сохранение симптомов заболевания после удаления желчного пузыря - основной источник разочарования не только для пациентов, но и для хирургов. В исследовательских сериях, которые рассматривают ранние результаты операций по удалению желчного пузыря у больных дискинезией желчного пузыря сообщается о разрешении боли у 90 \% пациентов на протяжении первых 3 недель после операции $[8,9]$. Данные долгосрочных исследований выявили тенденцию к снижению удовлетворенности результатами этих хирургических вмешательств на основании того, что у многих пациентов сохраняются жалобы, отмеченные до операции. В исследовании, проведенном в двух хирургических центрах, было изучено качество жизни пациентов с удаленным желчным пузырем в среднем на протяжении 3,7 года после операции. Итоги исследований свидетельствовали, что после холецистэктомии боль отсутствовала у 60 \% пациентов [10]. Большинство больных и их родителей были удовлетворены операцией, потому что это сузило фокус диагностических и лечебных процедур в поиске иных источников боли и в лечении болевого абдоминального синдрома. По-прежнему ведутся дискуссии о выборе рационального лечебно-диагностического подхода к этим пациентам. Некоторые хирурги предлагают ограничивать показания к хирургическому лечению детей с билиарной дискинезией, в то время как другие склоняются к ранней операции, чтобы своевременно отсеять пациентов с другими заболеваниями [11]. Не существует надежного предоперационного предиктора того, что после холецистэктомии, выполненной по поводу дискинезии желчевыводящих путей, произойдет клиническое улучшение, поэтому важно до операции информировать семью ребенка, что абдоминальные симптомы могут не исчезнуть после удаления желчного пузыря.

Существуют редкие варианты функциональных расстройств, при которых у пациентов появляются симптомы дискинезии желчевыводящих путей на фоне аномально высокой фракции выброса желчного пузыря, определенной с помощью HIDA-сканирования. Это состояние обозначается как гиперкинетическая дискинезия желчевыводящих путей. Представлено только одно сообщение, содержащее данные о небольшой серии случаев лечения таких пациентов, результаты которого 
свидетельствуют, что после выполнения холецистэктомии происходит облегчение течения болезни и снижение выраженности симптомов [12].

\section{ЖЕАЧНОКАМЕННАЯ БОАЕЗНЬ}

Ряд причин приводит к образованию камней желчного пузыря у детей. Частота случаев холелитиаза увеличивается в зависимости от распространенности ожирения, которое в развитых странах принимает черты эпидемии. Избыток холестерина в крови, сопровождающийся перенасыщением им желчи, приводит к образованию холестериновых камней, что является наиболее распространенной причиной образования камней или сладжей у детей. Другой распространенной формой холелитиаза у детей являются пигментированные камни, которые наблюдаются при заболеваниях крови, сопровождающихся гемолизом, таких как серповидноклеточная анемия, наследственный сфероцитоз и талассемия. На долю этих заболеваний приходится около 15 \% педиатрических пациентов с желчнокаменной болезнью [1]. Повышенный билирубин конъюгирует с кальцием, что приводит к образованию пигментированных камней в этих случаях. Другие, более редкие причины развития желчнокаменной болезни у детей включают длительное полное парентеральное питание, дегидратацию, муковисцидоз, синдром короткой кишки, резекцию подвздошной кишки и использование оральных контрацептивов в группе подростков $[4,5]$.

В соответствии с вышеизложенным клинические проявления желчнокаменной болезни будут сходными с симптомами дискинезии желчевыводящих путей, за исключением ситуаций, связанных с переходом процесса в стадию воспаления желчного пузыря. В младшем возрасте симптомы в виде тошноты и рвоты превалируют над классическим абдоминальным болевым синдромом. В целом, только у $60 \%$ детей и подростков с желчнокаменной болезнью выявляются специфические клинические симптомы [13]. УЗИ брюшной полости характеризуются $95 \%$ чувствительностью и специфичностью при выявлении камней в желчном пузыре, при том что точность результатов данных исследований у детей ниже, чем у взрослых $[14,15]$. Кроме того, УЗИ позволяют идентифицировать камни общего желчного и печеночных протоков, признаки воспаления желчного пузыря и другие на- рушения, относящиеся к патологии печени и поджелудочной железы. Информативность компьютерной томографии ограничена в диагностике желчнокаменной болезни и сопровождается лучевой нагрузкой на пациентов. Если при проведении УЗИ выявляются камни, сопровождающиеся выраженным утолщением стенки желчного пузыря (>4 мм), отеком и скоплением жидкости вокруг желчного пузыря, этого достаточно для диагностики острого холецистита. Пациентам с клиническими признаками острого холецистита, при том что результаты УЗИ не позволили выявить наличия конкрементов, проведение магнитно-резонасного томографического исследования позволяет установить наличие острого акалькулезного холецистита. Радионуклидное исследование имеет низкую диагностическую ценность в связи с тем, что у больных холециститом радиоактивные изотопы выделяются печенью, но не попадают в желчный пузырь из-за обструкции пузырного протока.

\section{ОСОБЕННОСТИ ЗАБОАЕВАНИЙ ЖЕАЧНОГО ПУЗЫРЯ У АЕТЕЙ}

Заболевания желчного пузыря в детском возрасте характеризуются определенными отличиями в сравнении с течением соответствующих болезней у взрослых пациентов. Одним из таких примеров являются дети с серповидноклеточной анемией. Серповидноклеточная анемия - заболевание крови, которое обусловлено продукцией патологической формы гемоглобина S вместо нормального гемоглобина А. Гемоглобинопатия способствует патологической адгезии эритроцитов, создавая внутрисосудистые скопления красных кровяных клеток. Эти клеточные массы, а также сами патологически развитые эритроциты разрушаются в результате фильтрации крови в селезенке. Поскольку серповидные эритроциты характеризуются сниженной осмотической резистентностью, их механическая травматизация в кровотоке сопровождается гемолизом, что приводит к высокому уровню обмена гемоглобина, поэтому у этих пациентов даже в раннем возрасте могут образовываться камни в желчном пузыре на основе пигмента. У всех больных серповидноклеточной анемией существует риск возникновения криза, в том числе и торакального, который может быть смертельно опасным для ребенка. Обезвоживание, анемия и системное воспаление повы- 
шают риск осложнений заболевания. Поэтому рекомендуется, чтобы подготовка больных серповидноклеточной анемией к предстоящей операции удаления желчного пузыря основывалась на адекватной гидратации и переливании крови до приемлемого уровня гемоглобина, составляющего не ниже 10 мг/дл [16]. Недавний ретроспективный обзор литературы показал, что плановая холецистэктомия при желчнокаменной болезни у педиатрических пациентов с серповидноклеточной анемией снижает риск осложнений по сравнению с детьми, перенесшими неотложную операцию [17]. Мы подчеркиваем этот момент и не рекомендуем наблюдение за бессимптомными желчными камнями, обнаруженными у детей с серповидноклеточной анемией. Холецистит, холангит и панкреатит могут угрожать жизни этих пациентов в течении болезни.

Другим заболеванием, которое приводит к формированию камней в желчном пузыре, является наследственный сфероцитоз. Особого внимания заслуживают больные, которые подвергаются при этой болезни спленэктомии. Если пациента направляют на спленэктомию, необходимо выполнить УЗИ для исключения желчнокаменной болезни, поскольку удалять желчный пузырь будет относительно легко одновременно с селезенкой, если будут обнаружены камни в желчном пузыре. В том случае, когда при проведении УЗИ желчного пузыря не обнаружено камней, то превентивная холецистэктомия не будет показана, поскольку источник пигментированных камней можно контролировать в ходе консервативного лечения и наблюдения за развитием основного заболевания. В исследовании, изучавшем 17 пациентов со сфероцитарной анемией, у которых до операции камни в желчном пузыре не определялись, не было обнаружено развития желчнокаменной болезни после спленэктомии [18].

Важным обстоятельством, требующим обсуждения в рамках данного раздела, является панкреатит, сопутствующий желчнокаменной болезни у детей. Дети с камнями или сладжами в желчном пузыре, как и взрослые, могут страдать от панкреатита, определяющего первоначально необходимость консервативного лечения. Холецистэктомия в этой ситуации откладывается до снижения интенсивности болей и нормализации печеночных и панкреатических тестов. Однако известно, что у взрослых больных длительная выжидательная тактика характеризуется высоким риском развития рецидивирующего (хронического) панкреатита [19]. В настоящее время лапароскопическую холецистэктомию у данного контингента пациентов рекомендуют выполнять до выписки ребенка из госпиталя.

Заключительной темой, которую необходимо представить при рассмотрении желчнокаменной болезни у детей, является холедохолитиаз. В соответствии с результатами современных исследований примерно у $11 \%$ детей, подвергнутых холецистэктомии, обнаруживались камни общего желчного протока [20]. Во взрослой популяции пациентов с желчнокаменной болезнью и установленным или предполагаемым холедохолитиазом при лапароскопической холецистэктомии используется интраоперационная холангиография. Тем не менее у детей, где холедохолитиаз встречается чрезвычайно редко, нет доказательств ее регулярного использования, что является предметом дискуссий. Предположение об аномальной анатомии желчных ходов или наличии камня в желчных протоках, определяет необходимость детским хирургам рассмотреть целесообразность выполнения этого исследования. У детей с признаками, указывающими на холедохолитиаз, такими как желтуха, появление темной мочи и ахоличного стула, или УЗ-визуализация расширенных протоков без признаков камнеобразования и тем более выявлении камня общего желчного протока, существует необходимость дополнительного обследования. Спектр диагностических решений включает эндоскопическую ретроградную холангиопанкреатографию, а в ее отсутствие - открытую или лапароскопическую ревизию общего желчного протока. Во время проведения эндоскопической ретроградной холангиопанкреатографии может быть применена сфинктеротомия и удаление камня до выполнения лапароскопической холецистэктомии. Однако многие эндоскописты-педиатры не располагают этой техникой, поэтому в ряде детских больниц вынуждены прибегать к помощи взрослых специалистов. Если холедохолитиаз не подтвержден УЗИ, тогда методом визуализации камней в желчных протоках может быть магнитно-резонансная холангиопанкреатография. Она также будет эффективна для определения анатомии панкреатобилиарной системы. Наличие у детского хирурга устойчивых эндохирургических навыков позволяет совместить удаление желч- 
ного пузыря с лапароскопическим исследованием общего желчного протока [20]. Однако в затруднительных ситуациях лучшим вариантом будет наличие за спиной детского хирурга специалиста с большим опытом выполнения подобных операций у взрослых пациентов.

\section{ААПАРОСКОПИЧЕСКАЯ ХОАЕЦИСТЭКТОМИЯ}

Стремление детских хирургов к развитию малоинвазивной хирургии в значительной степени усилилось благодаря появлению операции лапароскопической холецистэктомии [21-25]. Лапароскопическая холецистэктомия, первоначально разработанная у взрослых пациентов, у детей, как правило, реализуется по следующей методике. Пациент находится на операционном столе в положении на спине. Два видеомонитора располагаются в головном конце стола. Орогастральная трубка предназначена для декомпрессии желудка. Однако это больше дань традиции, чем нечто необходимое, например установка мочевого катетера для предотвращения повреждения мочевого пузыря в момент наложения карбоперитонеума. Хирург обычно стоит с левой стороны от пациента.

В стандартном варианте применяют четырехпортовую технику лапароскопической холецистэктомии. Обычно используют 10-миллиметровую оптическую канюля для облегчения извлечения желчного пузыря после его удаления, которая устанавливается трансумбиликально. Однако у более юных пациентов может использоваться 5-миллиметровая оптическая система. Следующую 5-миллиметровую канюлю помещают в брюшную полость в области эпигастрия справа от средней линии, которая становится основным местом манипуляций для хирурга. Затем устанавливают два рабочих инструмента с атравматичными конфигурациями рабочих вставок, и эти инструменты можно погружать в полость брюшины без порта, поскольку их практически не заменяют во время операции. Кроме того, у детей первых пяти лет жизни могут использоваться 3-миллиметровые инструменты. Рабочие инструменты устанавливаются следующим образом: один - в правом подреберье, а другой - в нижних отделах живота справа. Тракция вверх, осуществляемая движением атравматичного зажима, размещенного в нижнем отделе живота спра- ва, позволяет смещать дно желчного пузыря краниально. Перемещение зажима, расположенного в правом подреберье, позволяет переместить устье желчного пузыря вниз и латерально так, чтобы обнажить треугольник Calot. Эти два движения, если они адекватны и выполнены правильно, устранят в большинстве случаев необходимость изменения положения тела пациента на операционном столе с целью перемещения внутренних органов под воздействием сил гравитации. Далее следует диссекция тканей без использования рассекающих инструментов («тупая» диссекция) с целью выделения пузырного протока и пузырной артерии. Важно правильно определить анатомию, чтобы обеспечить безопасность процедуры. Критическое поле зрения должно быть ограничено ключевыми структурами - общим печеночным протоком медиально, пузырным протоком внизу, желчным пузырем сбоку и печенью сверху [26-28]. Только после визуализации и идентификации этих критических структур пузырный проток можно лигировать эндоскопическими клипсами и затем пересечь. Артерия желчного пузыря выделяется как можно дистальнее, обычно, когда она входит в желчный пузырь, иногда после деления на переднюю и заднюю ветви. Лигирование артерии производится с особой аккуратностью и осторожностью. Это необходимо сделать деликатно, взяв в руки диссекционный зажим Maryland и выполнив монополярное прижигание артерии желчного пузыря. Затем желчный пузырь аккуратно выделяют из ложа до полного отделения от ткани печени, используя также монополярную коагуляцию. Область ложа желчного пузыря после его удаления следует осмотреть на предмет обеспечения дополнительного коагуляционного гемостаза. Если воспаление отсутствует, желчный пузырь обычно удаляют через слегка расширенный пупочный разрез в месте стояния оптического лапаропорта без использования эндоскопического мешка. В случае инфицирования стенок следует воспользоваться эвакуационными контейнерами.

\section{ОАНОПОРТОВАЯ ААПАРОСКОПИЧЕСКАЯ ХОАЕЦИСТЭКТОМИЯ У АЕТЕЙ}

Вскоре после того как детские хирурги начали выполнять первые операции с использованием единого лапароскопического доступа, холецистэктомия стала самой рас- 
пространенной однопортовой лапароскопической операцией [29]. При использовании этой технологии все инструменты, предназначенные для удаления желчного пузыря, вводятся через пупок. Это предполагает, что пупочный разрез имеет длину около 2 см. В США, странах Европы и России часто используются специально изготовленные портсистемы. Применяются два основных типа устройств: порт SILS (Covidien, Norwalk CT) или TriPort (Olympus America, Center Valley PA). Порт SILS - это порт-система, изготовленная из пенистого материала с тремя рабочими каналами. В отличие от него система TriPort изготавливается из твердого пластика, силиконовой мембраны и также содержит три рабочих канала. Четвертый дополнительный инструмент может быть расположен вдоль левой стороны порта. Лучше использовать удлиненную оптическую систему, чтобы головка камеры не мешала оперирующему хирургу выполнять сложные манипуляции. Некоторые хирурги не пользуются порт-системами и помещают оптическую систему и инструменты через отдельные проколы пупочной фасции. С этой целью используются низкопрофильные 5-миллиметровые отдельные порты. Независимо от техники установки и ориентации инструментов, принципы холецистэктомии являются такими же, как и те, что используют для традиционной мультипортовой лапароскопической холецистэктомии. Достаточно трудно повторно установить эти порты, поэтому лучше всего сразу обеспечить окончательный гемостаз и, если необходимо, ирригацию/аспирацию полости брюшины перед извлечением желчного пузыря.

Лапароскопический подход с использованием одного разреза вызвал большой энтузиазм после публикации первых результатов новой технологии. В проспективном рандомизированном исследовании, включающем 60 детей, было проведено сравнение лапароскопической однопортовой холецистэктомии и стандартной четырехпортовой техники [30].
Результаты этого исследования показали, что у детей, которым выполнена лапароскопическая холецистэктомия с использованием одного разреза, регистрировалось более продолжительное среднее время операции по сравнению со стандартной четырехпортовой техникой, а также повышение баллов оценки сложности операции этой процедуры (см. таблицу).

Кроме того, пациенты, перенесшие лапароскопическую однопортовую холецистэктомию, испытывали боль, требующую более высоких доз послеоперационной анальгезии. Полное восстановление больных после однопортовой холецистэктомии требовало также более значительных госпитальных финансовых расходов. Поскольку основным преимуществом, предполагаемым многими хирургами, является превосходящий мультипортовую операцию косметический результат, пациентам из этого исследования была выполнена объективная оценка рубцов по шкале Манчестер, проведенная в краткосрочной и долгосрочной перспективе. Результаты показали незначительное преимущество единого лапароскопического доступа в раннем периоде наблюдений, дополнительно нивелирующиеся через 18 мес. после операции [31]. Несколько подобных рандомизированных исследований было проведено у взрослых пациентов, в значительной степени подтверждающих эти результаты, включая увеличение продолжительности однопортовых операций. В обзоре Cochrane, охватывающем 9 рандомизированных исследований, произведено сопоставление параметров 427 пациентов, оперированных с использованием однопортовой техники, с данными 428 больных, у которых реализована мультипортовая холецистэктомия [32]. Был сделан вывод, что для выполнения однопортовой холецистэктомии требовалось гораздо больше времени, чем для производства стандартной лапароскопической операции. Результаты данного метаанализа также не подтверждали лучшего косметического эффекта единого лапароскопического доступа.

Сравнение параметров пациентов после однопортовой и четырехпортовой холецистэктомии

Operative Data Comparing Patients Undergoing Laparoscopic Cholecystectomy via a Single Incision Approach vs a Four Port Technique

\begin{tabular}{|l|c|c|c|}
\hline \multicolumn{1}{|c|}{ Параметр сравнения } & 1 порт $(n=30)$ & 4 порта $(n=30)$ & $p$ \\
\hline Длительность операции, мин & $68,6 \pm 22,1$ & $56,1 \pm 22,1$ & 0,03 \\
\hline $\begin{array}{l}\text { Сложность операции, баллы: } \\
\text { от 1 (просто) до 5 (сложно) }\end{array}$ & $2,7 \pm 1,0$ & $1,9 \pm 0,8$ & 0,005 \\
\hline
\end{tabular}

Примечание. Взято с разрешения авторов из [30]. 
Таким образом, существующие к настоящему времени научные данные не предполагают каких-либо преимуществ использования однопортовой холецистэктомии. Преимущества, потенциально получаемые от использования однопортового подхода, достаточно малы, чтобы детские хирурги повсеместно выполняли удаление желчного пузыря таким способом. Однако наиболее креативные представители профессионального сообщества могут позволить себе рутинное использование однопортовой холецистэктомии. Если у них в какойто момент операции возникнут технические трудности, то они всегда смогут установить дополнительные инструменты, которые облегчат выполнение технически более простой мультипортовой лапароскопической процедуры.

Независимо от метода, используемого для лапароскопического удаления желчного пузыря, при отсутствии сопутствующих заболеваний эти пациенты могут быть достаточно быстро выписаны из госпиталя [33-36].

\section{АОПОАНИТЕАЬНАЯ ИНФОРМАЦИЯ}

Конфликт интересов: рукопись не содержит информации, способной привести к конфликту интересов,

Финансирование: финансовая или любая другая поддержка отсутствует.

Conflict of interest: The authors of this article confirmed the lack of interest and financial support, which should be reported.

\section{АИТЕРАТУРА}

1. Walker SK, Maki AC, Cannon RM, et al. Etiology and incidence of pediatric gallbladder disease. Surgery. 2013;154(3):927-933. https://doi.org/ 10.1016/j.surg.2013.04.040.

2. Khoo AK, Cartwright R, Berry S, Davenport M. Cholecystectomy in English children: Evidence of an epidemic (1997-2012). J Pediatr Surg. 2014;49(2):284-288. https://doi.org/10.1016/j.jpedsurg.2013.11.053.

3. Lacher M, Yannam GR, Muensterer OJ, et al. Laparoscopic cholecystectomy for biliary dyskinesia in children: Frequency increasing. J Pediatr Surg. 2013;48:1716-1721. https://doi.org/10.1016/j.jpedsurg.2012.08.036.

4. Friesen CA, Neilan N, Daniel JF, et al. Mast cell activation and clinical outcome in pediatric cholelithiasis and biliary dyskinesia. BMC Res Notes. 2011;4:322. https://doi.org/10.1186/1756-0500-4322.
5. Rau B, Friesen CA, Daniel JF, et al. Gallbladder wall inflammatory cells in pediatric patients with biliary dyskinesia and cholelithiasis: A pilot study. $\mathrm{J} \mathrm{Pe}-$ diatr Surg. 2006;41(9):1545-1548. https://doi.org/ 10.1016/j.jpedsurg.2006.05.015.

6. Srinath AI, Youk AO, Bielefeldt K. Biliary dyskinesia and symptomatic gallstone disease in children: Two sides of the same coin? Dig Dis Sci. 2014;59(6):1307-1315. https://doi.org/10.1007/ s10620-014-3126-2.

7. Williams K, Baumann L, Abdullah F, et al. Variation in prophylactic antibiotic use for laparoscopic cholecystectomy: need for better stewardship in pediatric surgery. J Pediatr Surg. 2018:53(1):48-51. https://doi.org/10.1016/j.jpedsurg.2017.10.012.

8. Lai SW, Rothenberg SS, Kay SM, et al. Outcomes of laparoscopic cholecystectomy for biliary dyskinesia in children. J Laparoendosc Adv Surg Tech A. 2017;27(8):845-850. https://doi.org/10.1089/ lap.2016.0338.

9. St. Peter SD, Keckler SJ, Nair A, et al. Laparoscopic cholecystectomy in the pediatric population. J Laparoendosc Adv Surg Tech A. 2008;18(1):127130. https://doi.org/10.1089/lap.2007.0150.

10. Knott EM, Fike FB, Gasior AC, et al. Multi-institutional analysis of long-term symptom resolution after cholecystectomy for biliary dyskinesia in children. Pediatr Surg Int. 2013;29:1243-1247. https://doi.org/10.1007/s00383-013-3343-3.

11. Cairo SB, Aranda A, Bartz-Kurycki M, et al. Variability in perioperative evaluation and resource utilization in pediatric patients with suspected biliary dyskinesia: A multi-institutional retrospective cohort study. J Pediatr Surg. 2019;54(6):1118-1122. https://doi.org/10.1016/j. jpedsurg.2019.02.049.

12. Dekonenko C, Sujka JA, Dorman RM, et al. Selfreported Outcomes After Cholecystectomy for Pediatric Hyperkinetic Biliary Dyskinesia. J Surg Res. 2020;246:73-77. https://doi.org/10.1016/j. jss.2019.06.088.

13. Kirsaclioglu CT, Cakir BC, Bayram G, et al. Risk factors, complications and outcome of cholelithiasis in children: A retrospective, single-centre review. J Paediatr Child Health. 2016;52(10):944949. https://doi.org/10.1111/jpc.13235.

14. Cooperberg PL, Burhenne HJ. Real-time ultrasonography - Diagnostic technique of choice in calculous gallbladder disease. $N$ Engl J Med. 1980;302:1277-1279. https://doi.org/10.1056/ NEJM198006053022303.

15. Tsai J, Sulkowski JP, Cooper JN, et al. Sensitivity and predictive value of ultrasound in pediatric cholecystitis. J Surg Res. 2013;184(1):378-382. https://doi.org/10.1016/j.jss.2013.03.066. 
16. Rhodes MM, Bates DG, Andrews T, et al. Abdominal pain in children with sickle cell disease. J Clin Gastroenterol. 2014;48(2):99-105. https:// doi.org/10.1097/01.mcg.0000436436.83015.5e.

17. Goodwin EF, Partain PI, Lebensburger JD, et al. Elective cholecystectomy reduces morbidity of cholelithiasis in pediatric sickle cell disease. Pediatr Blood Cancer. 2017;64(1):113-120. https://doi.org/ $10.1002 / \mathrm{pbc} .26179$.

18. Sandler A, Winkel G, Kimura K, Soper R. The role of prophylactic cholecystectomy during splenectomy in children with hereditary spherocytosis. J Pediatr Surg. 1999;34(7):1077-1078. https://doi.org/10.1016/s0022-3468(99)90569-9.

19. Knott EM, Gasior AC, Bikhchandani J, et al. Surgical management of gallstone pancreatitis in children. J Laparoendosc Adv Surg Tech A. 2012;22(5):501-504. https://doi.org/10.1089/ lap.2011.0514.

20. Hill SJ, Wulkan ML, Parker PM, et al. Management of the pediatric patient with choledocholithiasis in an era of advanced minimally invasive techniques. J Laparoendosc Adv Surg Tech A. 2014;24(1):38-42. https://doi.org/10.1089/lap.2013.0306.

21. Reynolds W, Jr. The first laparoscopic cholecystectomy. JSLS. 2001;5:89-94.

22. Dubois F, Berthelot G, Levard H. Cholecystectomy by coelioscopy. Presse Med. 1989;18:980982.

23. Reddick EJ, Olsen DO. Laparoscopic laser cholecystectomy. A comparison with mini-lap cholecystectomy. Surg Endosc. 1989;3:131-133. https://doi.org/10.1007/bf00591357.

24. McKernan JB. Laparoscopic cholecystectomy. Am Surg. 1991;57:309-312.

25. Holcomb GW, III, Olsen DO, Sharp KW. Laparoscopic cholecystectomy in the pediatric patient. J Pediatr Surg. 1991;26(10):1186-1190. https://doi.org/10.1016/0022-3468(91)90330-v.

26. Strasberg SM, Hertl M, Soper NJ. An analysis of the problem of biliary injury during laparoscopic cholecystectomy. J Am Coll Surg. 1995;180:101-125.

27. Vettoretto N, Saronni C, Harbi A, et al. Critical view of safety during laparoscopic cholecystectomy.
JSLS. 2011;15(3):322-325. https://doi.org/10.4293/ $108680811 X 13071180407474$.

28. Strasberg SM, Brunt LM. Rationale and use of the critical view of safety in laparoscopic cholecystectomy. J Am Coll Surg. 2010;211(1):132-138. https://doi.org/10.1016/j.jamcollsurg.2010.02.053.

29. Garey CL, Laituri CA, Ostlie DJ, et al. Singleincision laparoscopic surgery in children: initial single-center experience. J Pediatr Surg. 2011;46(5):904-907. https://doi.org/10.1016/j.jpedsurg.2011.02.020.

30. Ostlie DJ, Juang OO, Iqbal CW, et al. Single incision versus standard 4-port laparoscopic cholecystectomy: A prospective randomized trial. J Pediatr Surg. 2013;48(1):209-214. https://doi.org/10.1016/j.jpedsurg.2012.10.039.

31. Gasior AC, Knott EM, Holcomb GW, III, et al. Patient and parental scar assessment after single incision versus standard 3-port laparoscopic appendectomy: Long-term follow-up from a prospective randomized trial. J Pediatr Surg. 2014;49(1):120-122. https://doi.org/10.1016/j.jpedsurg.2013.09.041.

32. Gurusamy KS, Vaughan J, Rossi M, Davidson BR. Fewer-than-four ports versus four ports for laparoscopic cholecystectomy. Cochrane Database Syst Rev. 2014;(2):CD007109. https://doi.org/10.1002/14651858.CD007109.pub2.

33. Vaughan J, Nagendran M, Cooper J, et al. Anaesthetic regimens for day-procedure laparoscopic cholecystectomy. Cochrane Database Syst Rev. 2014;(1):CD009784. https://doi.org/10.1002/14651858.CD009784.pub2

34. Dalton BG, Gonzalez KW, Knott EM, et al. Same day discharge after laparoscopic cholecystectomy in children. J Surg Res. 2015;195(2):418-421. https://doi.org/10.1016/j.jss.2015.02.024.

35. Gould JL, Poola AS, St. Peter SD, Aguayo P. Same day discharge protocol implementation trends in laparoscopic cholecystectomy in pediatric patients. J Pediatr Surg. 2016;51(12):1936-1938. https://doi.org/10.1016/j.jpedsurg.2016.09.008.

36. Li Z, Zhao Q, Bai B, et al. Enhanced Recovery After Surgery Programs for Laparoscopic Abdominal Surgery: A Systematic Review and Meta-analysis. World J Surg. 2018;42:3463-3473. https://doi.org/10.1007/s00268-018-4656-0. 
Шаун Сант Питер - старший вице-президент детской больницы милосердия, профессор хирургии медицинского факультета. Университет Миссури-Канзас-Сити, Канзас-Сити, Миссури, США. ORCID iD: https://orcid.org/0000-0002-6140-9016.

Юрий Андреевич Козлов - заведующий отделением хирургии новорожденных, ОГАУЗ ИМДКБ, г. Иркутск; профессор кафедры детской хирургии, ГБОУ ВПО ИГМУ г. Иркутск; профессор кафедры ГБОУ ВПО ИГМАПО, г. Иркутск. ORCID iD: https://orcid.org/00000003-2313-897X. E-mail: yuriherz@hotmail.com.
Shawn D. St. Peter - Senior Vice President at Children's Mercy Hospital, Professor of Surgery, University of Missouri-Kansas City School of Medicine, Kansas City, Missouri, United States. ORCID iD: https://orcid.org/00000002-6140-9016.

Yury A. Kozlov - head of department of neonatal surgery, Municipal Pediatric Clinical Hospital, Irkutsk, Russia; Professor of the department of pediatric surgery, Irkutsk State Medical University Russia, Irkutsk, Russia; Professor of the department of pediatric surgery at Irkutsk State Medical Academy of Continuing Education, Irkutsk, Russia. ORCID iD: https://orcid.org/0000-0003-2313-897X. E-mail: yuriherz@hotmail.com. 